\title{
Psychometric design and validation of a tool to assess the medication administration process through simulation in undergraduate nursing students
}

\author{
M. Raurell-Torredà a,b, A. Bonmatí-Tomás ${ }^{c, *}$, M. Lamoglia-Puig ${ }^{\text {b,c,d }}$, I. Zaragoza-García e , M. Farrés-Tarafa ${ }^{\text {b,f }}$, \\ J. Roldán-Merino ${ }^{\mathrm{f}}$, R. Gómez-Ibañez ${ }^{\mathrm{b}, \mathrm{g}}$ \\ a School of Nursing, Faculty of Medicine and Health Sciences, University of Barcelona, Spain \\ ${ }^{\mathrm{b}}$ Research group on simulation (2017 GRE 231), Spain \\ ${ }^{\mathrm{c}}$ Faculty of Nursing, University of Girona, Spain \\ d Blanquerna Faculty of Health Sciences Ramon Llull University, Spain \\ ${ }^{\mathrm{e}}$ Faculty of Nursing, Physiotherapy and Chiropody, Complutense University of Madrid, Spain \\ ${ }^{\mathrm{f}}$ Sant Joan de Déu Campus - Private Foundation, University of Barcelona, Spain \\ ${ }^{g}$ Department of Nursing, Faculty of Medicine, Autonomous University of Barcelona, Spain
}

\section{A R T I C L E I N F O}

\section{Keywords}

Medication error

Simulation training

Nursing students

Validation study

\begin{abstract}
A B S T R A C T
Background: Medication errors account for 38\% of adverse events reported among undergraduate nursing students. Simulation provides training for nursing students in the medication administration process. However, there is a lack of reliable and valid instruments to measure its assessment.

Objectives: To design and validate a new tool (MEDICORRECT) to assess undergraduate nursing students in the medication administration process using a high-fidelity simulation scenario.

Design and methods: Study participants were fourth year undergraduate nursing students at the University of Barcelona. Phase 1 consisted of tool design and drafting, and content validity and feasibility analyses. Phase 2 covered construct validity and interrater reliability. A factor analysis was conducted, involving a principal component analysis and varimax rotation.

Findings: Of 21 initial items, 11 were eliminated because of low content validity ratio, 4 of which assessed cognitive skills such as administering the right medicine at the right dose, which were impossible to observe in the simulation scenario. The final version of MEDICORRECT contained 10 items. The exploratory factor analysis identified a four-factorial model explaining $67.3 \%$ of the variance. Interrater agreement measured with Kappa was greater than 0.70 for $80 \%$ of items.

Conclusions: The 10 items in MEDICORRECT are relevant and feasible, have suitable psychometric properties and reflect the practical skills identified in the medication administration process. The tool excludes cognitive skills, which should be included and assessed during prebriefing.
\end{abstract}

\section{Introduction}

According to recent reports, medical errors - some of which are medication-related - are now the third leading cause of death in the United States (Makary and Daniel, 2016). To address the issue of medication errors, the World Health Organisation launched a "Medication Without Harm" campaign in 2017 to increase awareness of medication use and safety. The call for action is "KNOW. CHECK. ASK." (WHO, 2017). The goal is to motivate patients, caregivers and health professionals (nurses, physicians and pharmacists) to take an active role to ensure the safety of the medication management process, which covers prescribing, documenting, dispensing, administering and monitoring (Hicks and Becker, 2012). Most medication errors are pre- ventable (Hewitt et al., 2015). According to Harris et al. (2014) and Whitehair et al. (2014), medication errors are more prevalent in the administration phase, and few are intercepted because there is usually no intermediary between the nurse and patient to detect errors at this point (Anderson, 2011; Bates, 2007).

Nurses are responsible for administering medication safely and effectively (WHO, 2011) and 40\% of their tasks involve medication administration (Hewitt et al., 2015). Acquiring competence in this area requires a combination of theoretical and practical knowledge and decision-making skills (Sulosaari et al., 2012). Theoretical knowledge includes pathophysiology, pharmacology and mathematics, which are all involved in drug calculations (Coyne et al., 2013). Nurses should also apply their clinical reasoning to assess a patient's status and thus

* Corresponding author.

E-mail address: anna.bonmati@udg.edu (A. Bonmatí-Tomás) 
improve the medication administration process (Rhode and Rohde and Domm, 2018).

Practical competence involves complying with the 10 rights (10 "Rs") of drug administration (Edwards and Axe, 2015), which cover the classic 5 Rs (Manias et al., 2014; Lapkin et al., 2016) with the goal of correctly preparing and administering the right drug to the right patient, at the right dose, route and time, and add the following: the right pharmacological knowledge and clinical judgement to check the medication is indicated for the patient's clinical condition, acting on a patient's refusal to take the drug, monitoring the right response after administration, and informing the patient on medication effects to increase patient safety. Clinical placements provide an excellent setting to practise medication management and administration, but such placements vary considerably depending on the clinical setting and supervisors' attitudes (Sulosaari et al., 2012). Students report that in a clinical setting tutors expect them to be more competent in the medication administration process than they are, corroborating the gap between classroom learning and healthcare institution needs (Monaghan, 2015). Other teaching strategies such as simulation, technology-enhanced methods, and online learning have demonstrated effectiveness in fostering the medication administration safety skills of nursing students (Lee and Quinn, 2019).

Simulation permits students to practise the medication administration process in a clinical setting that resembles real life but is exempt from patient risk. Tutors can give immediate feedback during simulated learning, which can be applied when students transfer competencies acquired in their degree course to clinical practice (Larue et al., 2015; Raurell-Torredà et al., 2014; Zimmerman and House, 2016).

Therefore, training through simulation can generate an ongoing culture of safety throughout undergraduate and postgraduate nursing education, ultimately leading to enhanced patient safety in the real world, which is the outcome sought at level four of the Kirkpatrick (2006) model. Simulation is increasingly prevalent in undergraduate nursing courses (Shin et al., 2015) and its values on nurse medication errors has been corroborated in various studies (Konieczny, 2016; Kuo et al., 2020; Mariani et al., 2017; Muroi et al., 2017; Sanko and McKay, 2017; Whitehair et al., 2014; Zimmerman and House, 2016). However, there is a lack of use of reliable and valid instruments to measure outcome variables (Lee and Quinn, 2019). For this reason, the aim of this study was to design and validate a new tool, which we named MEDICORRECT, to assess undergraduate nursing students in the medication administration process using a high-fidelity simulation scenario.

\section{Materials and methods}

\subsection{Design}

A quantitative and descriptive design was employed for this study, which was divided into two phases. In phase 1, MEDICORRECT was designed and drafted, and its content validity was analysed for relevance, comprehensiveness and feasibility. In phase 2 , construct validity and interrater reliability were analysed.

\subsection{Procedure}

Phase 1: Design, drafting and content validity analysis of MEDICORRECT.

The first version of the MEDICORRECT tool was created from a literature review of similar instruments (Cazzell and Howe, 2012; Daupin et al., 2016; Davies et al., 2019; Goodstone and Goodstone, 2013; Sanko and Mckay, 2017). The most common errors mentioned in clinical guidelines on preventing medication errors (ASHP, 1993; NCMERP, 2018) (see Fig. 1) were analysed together with the competencies in medication safety that undergraduate nursing students should acquire, based on the Rs (Latimer et al., 2017). However, regarding the practice of medication administration Rs, standardisation is lacking. In the USA, 10 Rs are mostly used (Kee et al., 2015) while in Australia, 6 Rs are applied (Australian Commission on Safety and Quality in Health Care., 2014). Other authors, such as Manias et al. (2014) and Lapkin et al. (2016) report on 5 Rs. However, applying discretion in medication administration, particularly through the 10 Rs approach, enhances the complex thought processes required, which can benefit professionals and patients alike by ensuring safe practice (Edwards and Axe, 2015).

As a result, version 1 of MEDICORRECT (V1) had a total of 23 items.

\subsection{Content validity}

In the content validity step, the tool items were checked for relevance and comprehensiveness, and for the integration of all dimensions and domains of the underlying construct. Validity was analysed at two levels:

1. By relevance:

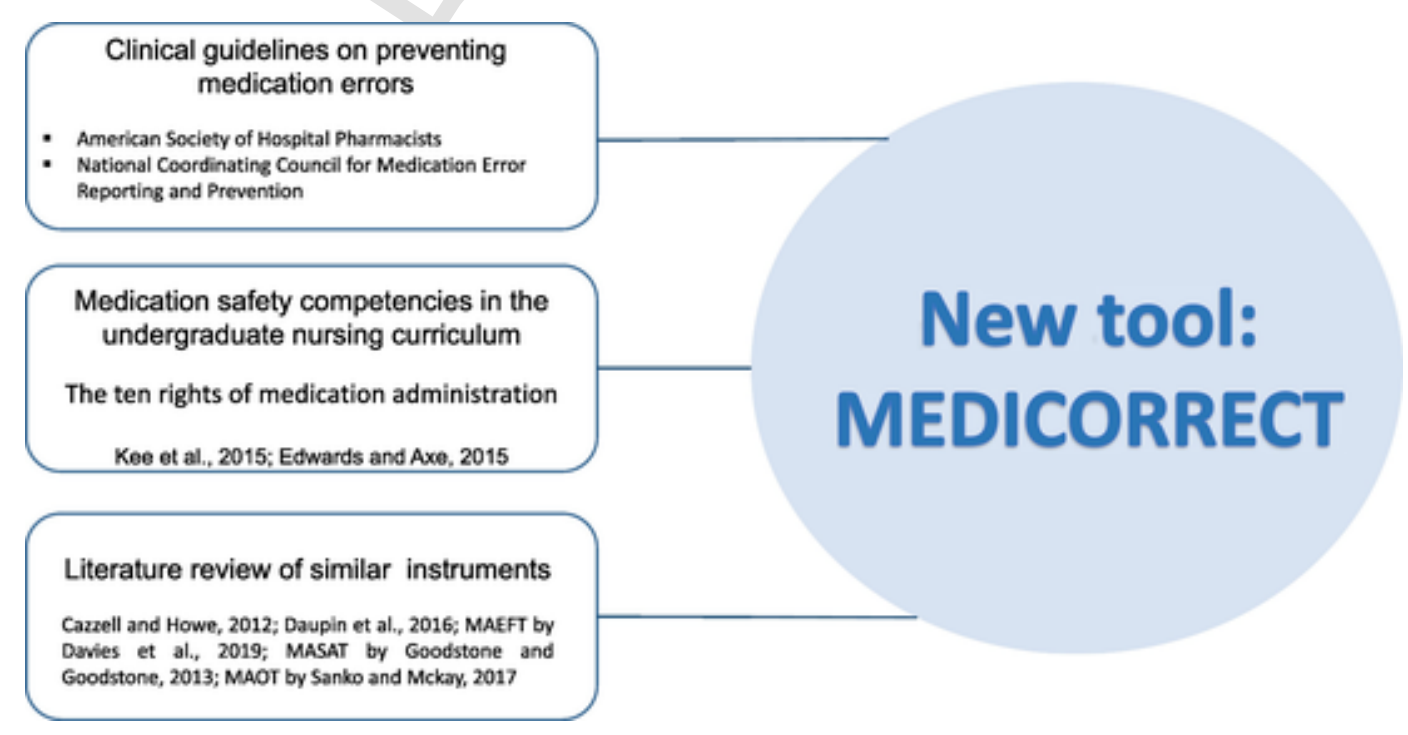

Fig. 1. TheoreticalframeworkbehindMEDICORRECT. 
To check that a tool explores all the dimensions and domains of the underlying construction, Norman and Streiner (2008) recommend using a sample of experts 5 to 20 times the number of items. MEDICORRECT (V1) had 23 items and therefore a minimum sample of 115 experts in the medication administration process was required. Following the COSMIN guidelines (Mokkink et al., 2019) a minimum of 50 nurses was considered, because the target population was undergraduate nursing students. Specifically, a total of 115 experts in the medication administration process took part, 79 of whom were nurses from various healthcare settings, 4 were anaesthetists, 11 were pharmacology lecturers for undergraduate nurses and 21 were pharmacists. The experts were given a Likert scale to complete for each item and were asked.

- if the item was relevant (where 1 was 'not at all relevant' and 4 was 'absolutely relevant').

- if the item was clearly written (where 1 was 'totally disagree' and 4 was 'totally agree')

Space was left beside each item to add any comments.

\section{By feasibility:}

To evaluate the feasibility of each item identified in the relevance analysis, 18 simulation experts participated from seven universities in Spain. These experts met the criteria suggested by Rizzolo et al. (2015): 1) simulation instructor with postgraduate training in learning and assessment methods, 2) a minimum of five years' experience in undergraduate nurse education and 3) two years using simulation as a methodology.

The experts analysed the feasibility of reproducing each item in a high-fidelity simulation setting and the possibility of assessing fulfilment of each item by videotaping. They were asked to score feasibility on a scale of 1 to 4 , where 1 was 'not at all feasible' and 4 was 'totally feasible'. Space was left beside each item to add any comments.

The content validity ratio (CVR) - understood as the degree of agreement among experts out of the total participating experts - was calculated for each item. A CVR of at least 0.58 was required to accept the experts' agreement for each item (Lawshe, 1975).

Phase 2: Analysis of the construct validity and interrater reliability of MEDICORRECT V1, created in Phase 1.

\subsubsection{Participants and setting}

Raters watched videotapes of simulation scenarios to analyse the construct validity of the tool. Fourth year undergraduate nursing students enrolled in the academic year 2018-19 performed the simulation. A total of 150 students were recruited through non-probability convenience sampling and all agreed to volunteer for the study. This sample size reflected the COSMIN guidelines (Mokkink et al., 2019) that recommend a minimum of 100 participants, or 5 to 20 participants per questionnaire item (Norman and Streiner, 2008; Tabachnick and Fidell, 2019). To achieve maximum objectivity, the videos were assessed by two lecturers who were not currently the participating students' instructors.

\subsubsection{Description of the intervention}

The research team designed six scenarios based on the NLN Jeffries simulation framework (Jeffries, 2016) involving the drugs most commonly associated with medication errors, as reported in the literature (Muroi et al., 2017; WHO, 2011). In line with the learning objectives for 4th year students, the six case scenarios were anaphylactic shock, sepsis of urinary origin, extensive acute myocardial infarction, complete atrioventricular block, complicated postoperative recovery of a femoral fracture, and pelvic fracture. A high-fidelity mannequin (hu- man patient simulator) was used for the case scenarios to integrate all nursing skills involved in the medication administration process, covering technical skills (required to accomplish a specific task) and non-technical skills alike (communication, situational awareness, decision-making, safe practice, adverse event minimisation and professionalism). The clinical cases were designed to integrate disease-specific pathophysiology with associated medication and the corresponding nursing interventions for students' level of knowledge (Raurell-Torredà et al., 2020). Packs were prepared in advance for each scenario and contained drug charts (to log pre- and post-administration actions) and labelled medication packages. Students were also supplied with intravenous giving sets with syringes, fluid bags and pumps, online access to medication information, and vital sign monitoring equipment. The simulation-based scenarios were recorded on digital videotapes.

\subsubsection{Variables and information source}

Variables included all the items identified in the MEDICORRECT questionnaire during phase 1 (content validity) as being relevant and feasible. Each item was marked as 'correct' or 'incorrect'. Sociodemographic variables were also collected, including age, sex, entry route to university, other university qualifications, and other health-related qualifications.

\subsubsection{Data analysis}

A principal component analysis was performed to study the underlying dimensions of item associations. As a preliminary step, the Kaiser-Meyer-Olkin measure and Bartlett's test of sphericity were applied to check goodness of fit for dimension reduction techniques. An optimum result was considered as Kaiser-Meyer Olkin $\geq 0.6$ and Bartlett's test $<0.05$ (Altman, 1992). According to the theoretical model and correlation values among the items, variables were expected to be independent. The correlation matrix and estimated factor loadings were therefore analysed using Varimax rotation.

Retained components were those with eigenvalues higher than the one showing a minimum of $10 \%$ variation. For the factor analysis, components with a standardized regression coefficient above 0.4 were identified.

Considering that an instrument is reliable if consistent results can be reproduced on different occasions, interrater reliability was investigated to measure the degree of agreement between raters. Cohen's kappa coefficient was used to calculate the agreement for each item between two raters. Kappa ranges from -1 to +1 and values greater than 0.70 denote good agreement (Landis and Koch, 1977).

\subsubsection{Ethical considerations}

The study was approved by the University of Barcelona Bioethics Board under code IRB00003099. The participants were informed about the authorship and purpose of the research project. They were assured that all the data obtained would remain confidential and signed a written informed consent form.

\section{Results}

\subsection{Phase 1: Content validity analysis}

The first part of the content validity analysis, on relevance and comprehensiveness, resulted in a 21 -item second version (V2) of the MEDICORRECT tool. Two items were eliminated from the original 23 items because they were too general and were also covered by other items. Based on the experts' suggestions, 18 items were edited to improve readability for raters during the simulation scenario. Table 1 shows the 21 items included, as graded by the experts. 
Table 1

Content validity of the items in the MEDICORRECT tool.

\begin{tabular}{|c|c|c|}
\hline $\begin{array}{l}\text { Item } \\
\text { relevance }\end{array}$ & Item description & $\begin{array}{l}\text { Item } \\
\text { feasibility }\end{array}$ \\
\hline 1 & $\begin{array}{l}\text { Double checks the patient's identification (full name } \\
\text { against medical record or date of birth through patient } \\
\text { questioning against checking the same details on the } \\
\text { patient's ID band) }\end{array}$ & 1 \\
\hline 2 & $\begin{array}{l}\text { Asks patients about allergies and intolerances (if } \\
\text { unresponsive, checks medical record and/or with } \\
\text { family) }\end{array}$ & 2 \\
\hline 3 & $\begin{array}{l}\text { Checks that the prescription matches the patient's } \\
\text { diagnosis (indications and contraindications) }\end{array}$ & Eliminated \\
\hline 4 & Questions a prescription if it is written incorrectly & Eliminated \\
\hline 5 & $\begin{array}{l}\text { Identifies and checks vital signs that may be affected by } \\
\text { the drug to be administered }\end{array}$ & 3 \\
\hline 6 & $\begin{array}{l}\text { Checks drug-related laboratory results before drug } \\
\text { administration }\end{array}$ & 4 \\
\hline 7 & Uses a drug guide if unfamiliar with the medication & Eliminated \\
\hline 8 & $\begin{array}{l}\text { Checks drug conditions (appearance, expiry date, } \\
\text { temperature) }\end{array}$ & Eliminated \\
\hline 9 & Reconstitutes the drug with the correct solution & Eliminated \\
\hline 10 & Calculates the drug as per the prescription & Eliminated \\
\hline 11 & $\begin{array}{l}\text { Double checks high-risk medications with a second } \\
\text { nurse }\end{array}$ & Eliminated \\
\hline 12 & $\begin{array}{l}\text { Labels the medication with the drug details (drug name } \\
\text { and dose) and patient details (full name) }\end{array}$ & 5 \\
\hline 13 & Performs hand hygiene and uses gloves if required & 6 \\
\hline 14 & $\begin{array}{l}\text { Disinfects the drug route of entry: connections and/or } \\
\text { skin }\end{array}$ & 7 \\
\hline 15 & Uses the correct equipment for drug administration & 8 \\
\hline 16 & Checks that the route of administration is correct & Eliminated \\
\hline 17 & $\begin{array}{l}\text { Checks the line is patent and administers a saline flush } \\
\text { afterwards, if applicable }\end{array}$ & Eliminated \\
\hline 18 & Offers the patient water in the case of oral drugs & Eliminated \\
\hline 19 & $\begin{array}{l}\text { Explains why the prescribed drug will not be } \\
\text { administered }\end{array}$ & Eliminated \\
\hline 20 & $\begin{array}{l}\text { Performs post-administration monitoring and } \\
\text { observation activities }\end{array}$ & 9 \\
\hline 21 & $\begin{array}{l}\text { Records the drug administered, the dose, route and } \\
\text { time }\end{array}$ & 10 \\
\hline
\end{tabular}

Items with Content Validity Ratio (CVR) $>0.58$ were accepted.

The second part of the content validity analysis, on feasibility (Fig. 2 ), resulted in 11 of the 21 initial items being eliminated because they had a CVR of less than 0.58 (Table 1 , column 3 ).

The experts' reasons for eliminating the items are detailed below and in general referred to evaluation impracticality, items beyond an undergraduate student's competence, and difficulties reproducing an item.

Items 3, 7 and 19 assessed a cognitive skill that was impossible to visualize on a videotape unless the student verbalised the process during the simulation. Item 11 (Double checks high-risk medications) could be assessed only in nurse-pair, not single-student scenarios.

Items 4 and 8 were unfeasible because an incorrect prescription or expired drug is confusing for undergraduate students and should not be used. Also, all drugs administered in case scenarios are simulation drugs and therefore have no expiry date. Similarly, simulation refrigerators are sometimes used and therefore these drugs may be room temperature.

Some items $(9,17,18)$ could not be reproduced in all medication administration processes covering various routes of administration (parenteral [intravenous, subcutaneous or intramuscular], by air [inhaled or nebulised] and oral/sublingual). Items 9 and 17 were specifically for intravenous drug prescriptions, and item 18 was for oral drug prescription. In addition, it was difficult to assess item 9 (Reconstitutes the

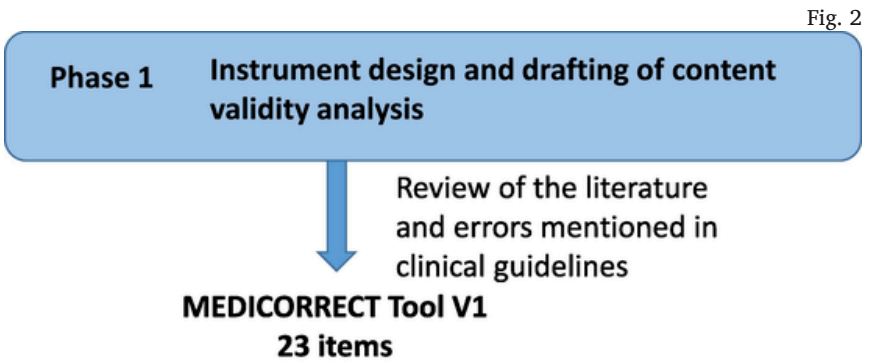

\section{Content validity 1: relevance} 115 experts in drug administration 79 nurses, 4 anaesthetists, 11 pharmacology lecturers and 21 pharmacists

\author{
MEDICORRECT TOol V2 \\ 21 items and 18 new edits \\ (table 1, column 1)
}

Content validity 2: feasibility 18 experts in simulation

\section{Medicorrect Tool \\ 10 items (table 1, column 3)}

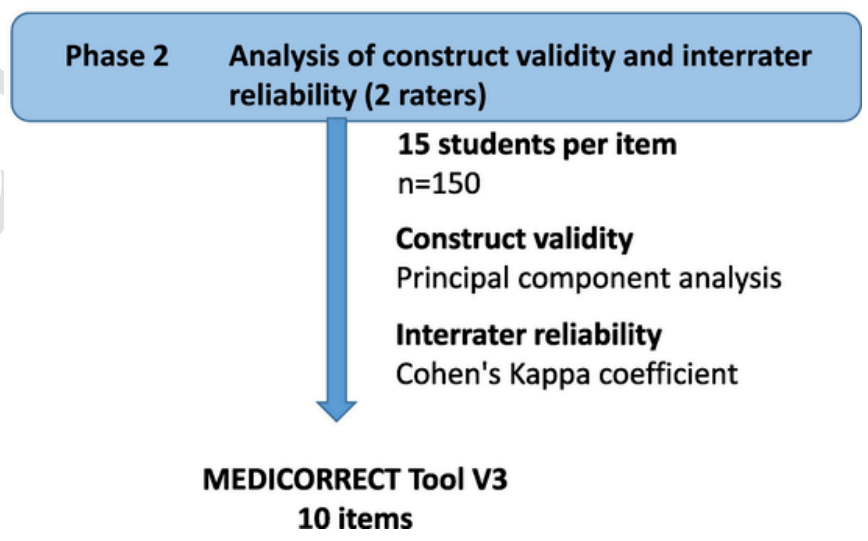

drug with the correct solution) unless the student verbalised the item, because it was impossible to know on videotape if the drug was being reconstituted correctly for the prescribed dosage.

Item 16 (Checks route of administration) was eliminated at the experts' suggestion because, unless the item was verbalised, it was impossible to know if the student was checking the route of administration. The experts suggested replacing this item with specific assessment criteria in item 15 , by clearly noting the equipment used: glass of water for oral drugs; no equipment but explanation to the patient for sublingual drugs; correct site localisation and needle angle for subcutaneous or intramuscular routes; bolus, microdrip set, infusion pump for intravenous administration; mask with chamber for nebulised drugs; single-dose device for inhaled drugs.

\subsection{Phase 2: Exploratory factor analysis}

A total of 150 students participated in this phase of the study. Mean age was 23.7 years (standard deviation 3.8 years) and $86.3 \%$ were women. The entry route to university was through standard examina- 
tion in $77.1 \%$ of students. Almost a tenth (8.4\%) of students already had other university qualifications.

Construct validity was based on an exploratory factor analysis to guide interpretation, using a principal component analysis with varimax rotation. A tetrachoric correlation matrix was applied in the exploratory factor analysis.

The Kaiser-Meyer-Olkin measure of sampling adequacy produced a value of 0.503 , confidence interval 95\% (range 0.430-0.583). Bartlett's test of sphericity was significant $(p<0.0001)$, showing that correlations between variables existed and that these correlations could be analysed ( $\mathrm{x} 2=427.04 ; \mathrm{df}=45 ; \mathrm{p}<0.0001$ ). The scree plot (Fig. 3) showed that $67.3 \%$ of the variance could be explained with four components. Table 2 shows correlations between items with a value greater than 0.4 , to help visualize how each item contributed to each factor. Items 1,8 and 10 were grouped in factor 1 (core items in the medication administration procedure), items 3 and 9 were grouped in in factor 2 (vigilance), items 2, 5 and 6 in factor 3 (patient safety) and items 4 and 7 in factor 4 (prevention).

\subsection{Interrater reliability}

Interrater agreement calculated using Cohen's Kappa coefficient was greater than 0.70 for all the items in the tool except numbers 1 and 4 (Table 3).

To improve interrater reliability, and after assessing 150 scenarios on videotapes, some clarifications were proposed for items 1, 4, 6 and 7, as reflected in MEDICORRECT tool V3, which had a final total of 10 items (Table 4).

Appendix I shows the cognitive skills that need to be assimilated and assessed in the prebriefing (supplementary material).

\section{Discussion}

Medication errors account for $38 \%$ of adverse events reported among undergraduate nursing students (García-Gámez et al., 2019). The actual number is probably higher due to underreporting by students fearful of having their marks brought down (Asensi-Vicente et al., 2018). Simulation is an excellent method to reduce medication er- rors, but more research is needed to develop reliable and valid instruments to evaluate nursing students' competencies in the field of patient safety, particularly in medication administration safety (Lee and Quinn, 2019).

The medication administration process is complex, encompassing multiple preparation steps and compliance with the five "Rs": giving the right drug to the right patient, at the right dose, route and time (Manias et al., 2014; Lapkin et al., 2016). The 10 "Rs" stem from a holistic, multi-disciplinary approach to the medication administration process (Edwards and Axe, 2015) and have been integrated in the MEDICORRECT tool, despite the added difficulty this brings to the simulation assessment, as noted by Daupin et al. (2016).

Because of this complexity, some relevant items cannot be assessed in a simulation scenario because they involve cognitive skills that would have to be verbalised by students. Verbalising out loud would have to be taught and would in fact be contradictory to the goal of imitating clinical practice in real life. For this reason, items that reflect cognitive skills, related to administering the right dose and the right medicine, cannot be assessed in a simulation scenario unless the student verbalises every decision taken during the drug preparation process.

A literature review by Sulosaari et al. (2012) reported that the longer the syllabus and the higher the grade achieved in high school mathematics, the fewer the errors made in dose calculations. Students have difficulties with dose calculation because of their poor mathematics skills (Gill et al., 2018; García-Gámez et al., 2019). Some authors, as noted in the review by García-Gámez et al. (2019), therefore recommend online reinforcement of dose calculations skills before students perform simulation exercises. The systematic review by Gill et al. (2018) also found that various studies have reported that students learn more pharmacology online than in person in the classroom. The same review recommends low-fidelity clinical case simulation, using a pen and paper to practise dose calculations.

Mariani et al. (2017) proposed providing training in cognitive skills - related to the right medicine and the right dose - at the prebriefing, which is defined by Meakim et al. (2013) as the information or orientation session held prior to the start of the simulation. The findings of this study corroborate the need to introduce cognitive skills in the prebriefing. Designing a prebriefing for a clinical case scenario involving training in dose calculation and online case-related pharmacological knowledge permits students to anticipate patients' needs and fo-

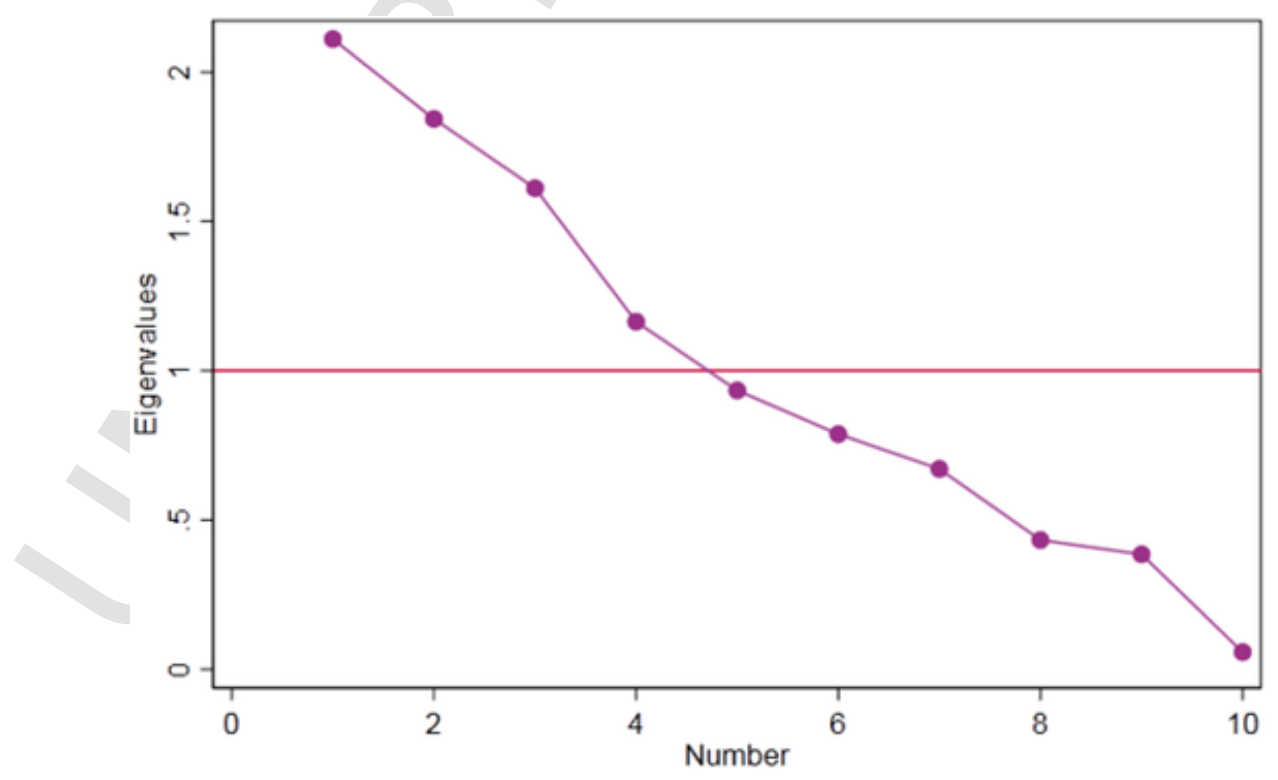

Fig. 3. Scree plot of eigenvalues after the factor analysis. 
Table 2

Exploratory factor analysis of the MEDICORRECT, using principal components analysis with a varimax rotation matrix.

\begin{tabular}{|c|c|c|c|c|c|c|}
\hline Items & & Commonality & $\begin{array}{l}\text { Factor } \\
1\end{array}$ & $\begin{array}{l}\text { Factor } \\
2\end{array}$ & $\begin{array}{l}\text { Factor } \\
3\end{array}$ & $\begin{array}{l}\text { Factor } \\
4\end{array}$ \\
\hline $\begin{array}{l}\text { Item } \\
1\end{array}$ & $\begin{array}{l}\text { Double checks } \\
\text { the patient's } \\
\text { identification } \\
\text { (full name } \\
\text { against } \\
\text { medical record } \\
\text { or date of birth } \\
\text { through } \\
\text { patient } \\
\text { questioning } \\
\text { against } \\
\text { checking the } \\
\text { same details on } \\
\text { the patient's ID } \\
\text { band) }\end{array}$ & 0.49 & 0.62 & & & \\
\hline $\begin{array}{l}\text { Item } \\
2\end{array}$ & $\begin{array}{l}\text { Asks patients } \\
\text { about allergies } \\
\text { and } \\
\text { intolerances (if } \\
\text { unresponsive, } \\
\text { checks medical } \\
\text { record and/or } \\
\text { with family) }\end{array}$ & 0.32 & & & 0.79 & \\
\hline $\begin{array}{l}\text { Item } \\
3\end{array}$ & $\begin{array}{l}\text { Identifies and } \\
\text { checks vital } \\
\text { signs that may } \\
\text { be affected by } \\
\text { the drug to be } \\
\text { administered }\end{array}$ & 0.40 & & 0.62 & & \\
\hline $\begin{array}{l}\text { Item } \\
4\end{array}$ & $\begin{array}{l}\text { Checks drug- } \\
\text { related } \\
\text { laboratory } \\
\text { results before } \\
\text { drug } \\
\text { administration }\end{array}$ & 0.47 & & & & 0.57 \\
\hline $\begin{array}{l}\text { Item } \\
5\end{array}$ & $\begin{array}{l}\text { Labels the } \\
\text { medication } \\
\text { with the drug } \\
\text { details (drug } \\
\text { name and } \\
\text { dose) and } \\
\text { patient details } \\
\text { (full name). }\end{array}$ & 0.29 & & & 0.82 & \\
\hline $\begin{array}{l}\text { Item } \\
6\end{array}$ & $\begin{array}{l}\text { Performs hand } \\
\text { hygiene and } \\
\text { uses gloves if } \\
\text { required }\end{array}$ & 0.31 & & & 0.54 & \\
\hline $\begin{array}{l}\text { Item } \\
7\end{array}$ & $\begin{array}{l}\text { Disinfects the } \\
\text { drug route of } \\
\text { entry: } \\
\text { connections } \\
\text { and/or skin }\end{array}$ & 0.31 & & & & 0.80 \\
\hline $\begin{array}{l}\text { Item } \\
8\end{array}$ & $\begin{array}{l}\text { Uses the } \\
\text { correct } \\
\text { equipment for } \\
\text { drug } \\
\text { administration }\end{array}$ & 0.09 & 00 & & & \\
\hline $\begin{array}{l}\text { Item } \\
9\end{array}$ & $\begin{array}{l}\text { Performs post- } \\
\text { administration } \\
\text { monitoring and } \\
\text { observation } \\
\text { activities }\end{array}$ & 0.24 & & 0.86 & & \\
\hline $\begin{array}{l}\text { Item } \\
10\end{array}$ & $\begin{array}{l}\text { Records the } \\
\text { drug } \\
\text { administered, } \\
\text { the dose, route } \\
\text { and time }\end{array}$ & 0.33 & 0.73 & & & \\
\hline
\end{tabular}

\begin{tabular}{lllll}
\hline Items & Commonality & $\begin{array}{l}\text { Factor } \\
1\end{array}$ & $\begin{array}{l}\text { Factor } \\
2\end{array}$ & $\begin{array}{l}\text { Factor } \\
3\end{array}$ \\
\hline $\begin{array}{l}\text { Percentage of variance } \\
\text { explained } \\
\text { Total variance explained }\end{array}$ & 20.5 & 17.3 & 16.4 \\
\hline
\end{tabular}

Table 3

Interrater agreement for MEDICORRECT.

\begin{tabular}{|c|c|c|c|}
\hline Item & & Kappa ${ }^{a}$ & $\begin{array}{l}\text { CI } \\
(95.0 \%)\end{array}$ \\
\hline $\begin{array}{l}\text { Item } \\
1\end{array}$ & $\begin{array}{l}\text { Double checks the patient's identification (full } \\
\text { name against medical record or date of birth } \\
\text { through patient questioning against checking the } \\
\text { same details on the patient's ID band) }\end{array}$ & 0.60 & $0.33-0.88$ \\
\hline $\begin{array}{l}\text { Item } \\
2\end{array}$ & $\begin{array}{l}\text { Asks patients about allergies and intolerances (if } \\
\text { unresponsive, checks medical record and/or with } \\
\text { family) }\end{array}$ & 0.75 & $0.56-0.94$ \\
\hline $\begin{array}{l}\text { Item } \\
3\end{array}$ & $\begin{array}{l}\text { Identifies and checks vital signs that may be } \\
\text { affected by the drug to be administered }\end{array}$ & 0.75 & $0.57-0.94$ \\
\hline $\begin{array}{l}\text { Item } \\
4\end{array}$ & $\begin{array}{l}\text { Checks drug-related laboratory results before drug } \\
\text { administration }\end{array}$ & 0.64 & $0,27-0.99$ \\
\hline $\begin{array}{l}\text { Item } \\
5\end{array}$ & $\begin{array}{l}\text { Labels the medication with the drug details (drug } \\
\text { name and dose) and patient details (full name). }\end{array}$ & 0.78 & $0.58-0.98$ \\
\hline $\begin{array}{l}\text { Item } \\
6\end{array}$ & Performs hand hygiene and uses gloves if required & 0.74 & $0.52-0.95$ \\
\hline $\begin{array}{l}\text { Item } \\
7\end{array}$ & $\begin{array}{l}\text { Disinfects the drug route of entry: connections and/ } \\
\text { or skin }\end{array}$ & 0.78 & $0.61-0.96$ \\
\hline $\begin{array}{l}\text { Item } \\
8\end{array}$ & Uses the correct equipment for drug administration & 0.73 & $0.48-0.98$ \\
\hline $\begin{array}{l}\text { Item } \\
9\end{array}$ & $\begin{array}{l}\text { Performs post-administration monitoring and } \\
\text { control activities }\end{array}$ & 0.84 & $0.69-0.99$ \\
\hline $\begin{array}{l}\text { Item } \\
10\end{array}$ & $\begin{array}{l}\text { Records the drug administered, the dose, route and } \\
\text { time }\end{array}$ & 0.77 & $0.59-0.96$ \\
\hline
\end{tabular}

CI: Confidence interval.

a A kappa coefficient greater than 0.70 denotes good agreement.

Table 4

Final items to assess the medication administration process in videotaped simulation scenarios (MEDICORRECT tool, V3).

\begin{tabular}{|c|c|}
\hline Item & Description \\
\hline 1 & $\begin{array}{l}\text { Double checks the patient's identification (full name against medical record } \\
\text { or date of birth through patient questioning* against checking the same } \\
\text { details on the patient's ID band) } \\
\text { *If the patient is unresponsive, checks against the medical record }\end{array}$ \\
\hline 2 & $\begin{array}{l}\text { Asks patients about allergies and intolerances (if unresponsive, checks } \\
\text { medical record and/or with family) }\end{array}$ \\
\hline 3 & $\begin{array}{l}\text { Identifies and checks vital signs that may be affected by the drug to be } \\
\text { administered }\end{array}$ \\
\hline 4 & $\begin{array}{l}\text { Checks drug-related laboratory results before drug administration } \\
\text { *Agree in the prebriefing which drugs require a laboratory results check }\end{array}$ \\
\hline 5 & $\begin{array}{l}\text { Labels the medication with the drug details (drug name and dose) and } \\
\text { patient details (full name) }\end{array}$ \\
\hline 6 & $\begin{array}{l}\text { Performs hand hygiene and uses gloves if required* } \\
\text { *As per the pre-simulation instruction brochure }\end{array}$ \\
\hline 7 & $\begin{array}{l}\text { Disinfects the drug route of entry: connections and/or skin } \\
\text { *In the case of oral drugs, this item is automatically considered correct }\end{array}$ \\
\hline 8 & $\begin{array}{l}\text { Uses the correct equipment for drug administration } \\
\text { Glass of water for oral drugs; no equipment but explanation to the patient } \\
\text { for sublingual drugs; correct site localisation and needle angle for } \\
\text { subcutaneous/intramuscular routes; bolus, microdrip set, infusion pump for } \\
\text { intravenous administration; mask with chamber for nebulised drugs; single- } \\
\text { dose device for inhaled drugs. }\end{array}$ \\
\hline 9 & Performs post-administration monitoring and observation activities \\
\hline 10 & Records the drug administered, the dose, route and time \\
\hline
\end{tabular}


cus their attention on applying prior knowledge, thereby achieving the simulation goals (Page-Cutrara, 2014). In the prebriefing, it is also recommended to cover the administration of drugs that depend on laboratory test results, such as anticoagulants (i.e., right medicine, right dose skills), as noted by Muroi et al. (2017). Also, students may benefit from watching a video on all the practical skills related to the medication administration process (Gill et al., 2018).

To improve interrater reliability, the recommendation by Cazzell and Howe (2012) should be followed, whereby raters become familiar with the checklist by assessing several practice videotapes before carrying out a real assessment. Raters should also review every item to avoid trivialisation bias. Videotape evaluations should be limited to 15 per day to avoid rater fatigue, which could interfere with the results. To increase the objectivity of the assessment, Cazzell and Howe (2012) recommend that raters should not act as course instructors for the same subject.

Unlike the Medication Administration Observation Tool (MAOT) an assessment tool created by Sanko and Mckay (2017), MEDICORRECT has no "right time" item because a simulation scenario is itself a given moment in time. The student has no access to the patient's medication administration record and the scenario is too short to assess whether the prescribed dosage interval is correct. However, if these factors are included in a scenario design, then it would be appropriate to add the "right time" item to the checklist.

The first version of MEDICORRECT included items from the Medication Administration Safety Assessment Tool (MASAT), by Goodstone and Goodstone (2013), and the Medication Administration Evaluation and Feedback Tool (MAEFT), by Davies et al. (2019). However, MEDICORRECT cannot be compared with them because MASAT included only the five basic "Rs" plus drug recording and MAEFT was validated in a population of qualified nurses participating in a standardized patient simulation scenario, while MEDICORRECT was validated for undergraduate nursing students.

\subsection{Limitations}

Our study has some limitations. The instrument's sensitivity to change could not be evaluated because the population consisted of students in a single academic year. It would be interesting to investigate whether the instrument detects students' improving medication administration process skills as they continue through their degree course.

A convenience sample of nursing students was taken from a single university in Barcelona, and it is therefore possible that the results cannot be generalised for all nursing students. However, the sociodemographic and characteristics of the students in this study are similar to other universities in Spain.

Finally, the results may be affected by the Hawthorne effect, simply because the participants know that they were being recorded. This influence is likely to be minimal because video cameras are permanently installed in the simulation laboratory; students are quite familiar with them and are able to ignore them.

\section{Conclusions}

The 10 items in the MEDICORRECT tool are relevant and feasible, have suitable psychometric properties, and reflect the practical skills required in the ten "Rs", permitting the medication administration process to be assessed by means of videotaped simulation scenarios. The instrument omits cognitive skills, which should be assessed during prebriefing.

Supplementary data to this article can be found online at https://doi. org/10.1016/j.nedt.2020.104726.

\section{Ethical approval}

The study was approved by the University's Ethics Committee under code IRB00003099.

\section{Funding source}

This work was supported by through the REDICE-18 Call for Research Grants for University Teaching at the Education Sciences Institute of the University of Barcelona.

\section{Uncited reference}

Bartlett, 1950

\section{Declaration of competing interest}

None declared.

\section{Acknowledgments}

We are grateful to the University of Girona for its contribution to data acquisition and instructors' collaboration.

\section{References}

Altman, Douglas G., 1992. Practical Statistics for Medical Research. Chapman and Hall, London.

American Society of Hospital Pharmacists (ASHP), 1993. ASHP guidelines on preventing medication errors in hospitals. Am. J. Hosp. Pharm. 50, 305-314. doi:10.1093/ajhp/ 50.2.305.

Anderson, P., 2011. Medication error: don't let them happen to you. Am. Nurse Today 5 (3) Retrieved April 5, 2017 from https://www.americannursetoday.com/medicationerrors-dont-let-them-happen-to-you/.

Asensi-Vicente, J., Jiménez-Ruiz, I., Vizcaya-Moreno, M.F., 2018. Medication errors involving nursing students: a systematic review. Nurse Educ. 43, E1-E5. doi:10.1097/ NNE.0000000000000481.

Australian Commission on Safety and Quality in Health Care, 2014. National Residential Medication Chart User Guide for Nursing and Care Staff. ACSQHC, Sydney Available from: https://www.safetyandquality.gov.au/sites/default/files/migrated/SAQ123 NursesUserGuide_V6.pdf. (Accessed 15 November 2020).

Bartlett, M.S., 1950. Test of significance in factor analysis. Br J Math Stat Psychol 3, 77-85. doi:10.1111/j.2044-8317.1950.tb00285.x.

Bates, D.W., 2007. Preventing medication errors: a summary. Am. J. Health Syst. Pharm. 64, S3-S9. doi:10.2146/ajhp070190.

Cazzell, M., Howe, C., 2012. Using objective structured clinical evaluation for simulation evaluation: checklist considerations for interrater reliability. Clin. Simul. Nurs. 8, e219-e225. doi:10.1016/j.ecns.2011.10.004.

Coyne, E., Needham, J., Rands, H., 2013. Enhancing student nurses' medication calculation knowledge; integrating theoretical knowledge into practice. Nurse Educ. Today 33, 1014-1019. doi:10.1016/j.nedt.2012.04.006.

Daupin, J., Atkinson, S., Bédard, P., Pelchat, V., Lebel, D., Bussières, J.F., 2016. Medication errors room: a simulation to assess the medical, nursing and pharmacy staffs' ability to identify errors related to the medication-use system. J Eval Clin Prac 22, 907-916. doi:10.1111/jep.12558.

Davies, K.M., Coombes, I.D., Keogh, S., Hay, K., Hurst, C., Whitfield, K.M., 2019. Medication administration evaluation and feedback tool: simulation reliability testing. Clin. Simul. Nurs. 32, 1-7. doi:10.1016/j.ecns.2019.03.010.

Edwards, S., Axe, S., 2015. The 10 'R's of safe multidisciplinary drug administration. Nurse Prescribing 13, 398-406. doi:10.12968/npre.2015.13.8.398.

García-Gámez, M., Morales-Asencio, J.M., García-Mayor, S., Kaknani-Uttumchandani, S., Marti-Garcia, C., Lopez-Leiva, I., León-Campos, A., Fernandez-Ordoñez, E., García-Guerrero, A., Iglesias-Parra, M.R., 2019. A scoping review of safety management during clinical placements of undergraduate nursing students. Nurs. Outlook 67, 765-775. doi:10.1016/j.outlook.2019.06.003.

Gill, M., Andersen, E., Hilsmann, N., 2018. Best practices for teaching pharmacology to undergraduate nursing students: a systematic review of the literature. Nurse Educ. Today 7, 15-24. doi:10.1016/j.nedt.2018.11.017.

Goodstone, L., Goodstone, M.S., 2013. Use of simulation to develop a medication administration safety assessment tool. Clin. Simul. Nurs. 9, e609-e615. doi:10.1016/ j.ecns.2013.04.017.

Harris, M.A., Pittiglio, L., Newton, S.E., Moore, G., 2014. Using simulation to improve the medication administration skills of undergraduate nursing students. Nurs. Educ. Perspect. 35, 26-29. doi:10.5480/11-552.1.

Hewitt, J., Tower, M., Latimer, S., 2015. An education intervention to improve nursing students' understanding of medication safety. Nurse Educ. Pract. 15 (1), 17-21. doi:10.1016/j.nepr.2014.11.001.

Hicks, R.W., Becker, S.C., 2012. Implementing AORN recommended practices for medication safety. AORN J. 96, 605-622. doi:10.1016/j.aorn.2012.09.012.

Jeffries, P.R., 2016. The NLN Jeffries Simulation Theory. National League for Nursing, Philadelphia, PA. 
Kee, J.L., Hayes, E.R., McCuistion, L.E., 2015. Pharmacology: A Patient-Centered Nursing Process Approach. eighth ed. Elsevier, St. Louis, MO.

Kirkpatrick, D.L., 2006. Evaluating Training Programs: The Four Levels. 3rd ed San Francisco, Bernett-Koehler.

Konieczny, L., 2016. Using high-fidelity simulation to increase nursing student knowledge in medication administration. Teach. Learn. Nurs. 11 (4), 199-203. doi:10.1016/ j.teln.2016.08.003.

Kuo, S.-Y., Wu, J.-C., Chen, H.-W., Chen, C.-J., Hu, S., 2020. Comparison of the effects of simulation training and problem-based scenarios on the improvement of graduating nursing students to speak up about medication errors: a quasi-experimental study. Nurse Educ. Today 87, 104359. doi:10.1016/j.nedt.2020.104359.

Landis, J.R., Koch, G.G., 1977. The measurement of observer agreement for categorical data. Biometrics 33, 159-174.

Lapkin, S., Levett-Jones, T., Chenoweth, L., Johnson, M., 2016. The effectiveness of interventions designed to reduce medication administration errors: a synthesis of findings from systematic reviews. J. Nurs. Manag. 24, 845-858. doi:10.1111/ jonm.12390.

Larue, C., Pepin, J., Allard, E., 2015. Simulation in preparation or substitution for clinical placement: a systematic review of the literature. J Nurs Educ Pract 5, 132-140. doi:10.5430/jnep.v5n9p132.

Latimer, S., Hewitt, J., Stanbrough, R., McAndrew, R., 2017. Reducing medication errors: teaching strategies that increase nursing students' awareness of medication errors and their prevention. Nurse Educ Today 52, 7-9. doi:10.1016/j.nedt.2017.02.004.

Lawshe, C.H., 1975. A quantitative approach to content validity. Pers. Psychol. 28 (4), 563-575. doi:10.1111/j.1744-6570.1975.tb01393.x.

Lee, S.E., Quinn, B.L., 2019. Incorporating medication administration safety in undergraduate nursing education: a literature review. Nurse Educ. Today 72, 77-83. doi:10.1016/j.nedt.2018.11.004.

Makary, M., Daniel, M., 2016. Medical error-the third leading cause of death in the US. BMJ 353. doi:10.1136/bmj.i2139.

Manias, E., Kinney, S., Cranswick, N., Williams, A., Borrott, N., 2014. Interventions to reduce medication errors in pediatric intensive care. Ann. Pharmacother. 48, 1313-1331. doi:10.1177/1060028014543795.

Mariani, B., Ross, J.G., Paparella, S., Allen, R.L., 2017. Medication safety simulation to assess student knowledge and competence. Clin. Simul. Nurs. 13, 210-216. doi:10.1016/j.ecns.2017.01.003.

Meakim, C., Boese, T., Decker, S., Franklin, A.E., Gloe, D., Lioce, L., Sando, C.R., Borum, J.C., 2013. Standards of best practice: simulation standard I: terminology. Clin. Simul. Nurs. 9, S3-S11. doi:10.1016/j.ecns.2013.04.001.

L.B. Mokkink C.A.C. Prinsen D.L. Patrick J. Alonso L.M. Bouter H.C.W. de Vet C.B. Terwee COSMIN Study Design checklist for Patient-reported outcome measurement instrumentsAvailable from:https://www.cosmin.nl/wp-content/uploads/COSMIN-studydesigning-checklist_final.pdf2019s 18 September 2020

Monaghan, T., 2015. A critical analysis of the literature and theoretical perspectives on theory-practice gap amongst newly qualified nurses within the United Kingdom. Nurse Educ. Today 35, e1-e7. doi:10.1016/j.nedt.2015.03.006.

Muroi, M., Shen, J.J., Angosta, A., 2017. Association of medication errors with drug classifications, clinical units, and consequence of errors: are they related? Appl. Nurs. Res. 33, 180-185. doi:10.1016/j.apnr.2016.12.00.
National Coordinating Council for Medication Error Reporting and Prevention (NCMERP) Taxonomy of medication errorsAvailable from:https://www.nccmerp.org/sites/ default/files/taxonomy2001-07-31.pdf2018s 29 March 2020

Norman, G.R., Streiner, D.L., 2008. Biostatistics: The Bare Essentials. 3rd ed B.C. Decker, Inc., Hamilton Ontario.

Page-Cutrara, K., 2014. Use of prebriefing in nursing simulation: a literature review. J. Nurs. Educ. 53, 136-141. doi:10.3928/01484834-20140211-07.

Raurell-Torredà, M., Olivet-Pujol, J., Romero-Collado, A., Malagon-Aguilera, M.C., Patiño-Masó, J., Baltasar-Bagué, A., 2014. Case-based learning and simulation: useful tools to enhance nurses' education? Nonrandomized controlled trial. J. Nurs. Scholarsh. 47, 34-42. doi:10.1111/jnu.12113.

Raurell-Torredà, M., Llauradó-Serra, M., Lamoglia-Puig, M., Rifà-Ros, R., Díaz-Agea, J.L., García-Mayor, S., Romero-Collado, A., 2020. Standardized language systems for the design of high-fidelity simulation scenarios: a Delphi study. Nurse Educ. Today 86, 104319. doi:10.1016/j.nedt.2019.104319.

Rizzolo, M.A., Kardong-Edgren, S., Oermann, M.H., Jeffries, P.R., 2015. The national league for nursing project to explore the use of simulation for high-stakes assessment: process, outcomes, and recommendations. Nurs. Educ. Perspect. 36, 299-303. doi:10.5480/15-1639.

Rohde, E., Domm, E., 2018. Nurses' clinical reasoning practices that support safe medication administration: an integrative review of literature. J. Clin. Nurs. 27, e402-e411. doi:10.1111/jocn.14077.

Sanko, J.S., Mckay, M., 2017. Impact of simulation-enhanced pharmacology education in prelicensure nursing education. Nurse Educ. 42, S32-S37. doi:10.1097/ NNE.0000000000000409.

Shin, S., Park, J.H., Kim, J.H., 2015. Effectiveness of patient simulation in nursing education: meta-analysis. Nurse Educ. Today 35, 176-182. doi:10.1016/ j.nedt.2014.09.009.

Sulosaari, V., Kajander, S., Hupli, M., Huupponen, R., Leino-Kilpi, H., 2012. Nurse students' medication competence-an integrative review of the associated factors. Nurse Educ. Today 32, 399-405. doi:10.1016/j.nedt.2011.05.016.

Tabachnick, B.G., Fidell, L.S., 2019. Using Multivariate Statistics. 7th ed New York, Pearson.

Whitehair, L., Provost, S., Hurley, J., 2014. Identification of prescribing errors by pre-registration student nurses: a cross-sectional observational study utilising a prescription medication quiz. Nurse Educ. Today 34, 225-232. doi:10.1016/ j.nedt.2012.12.010.

World Health Organization Patient safety curriculum guide: multi-professional editionAvailable from:http://whqlibdoc.who.int/publications/2011/9789241501958 eng.pdf2011s 29 March 2020

World Health Organization Global campaign: medication without harm fromhttps://www who.int/patientsafety/medication-safety/campaign/en/2017s 18 May 2020

Zimmerman, D.M., House, P., 2016. Medication safety: simulation education for new RNs promises an excellent return on investment. Nursing Econ 34, 49-51. 